\title{
Scientific and Technological Innovation Service Mode Based on Industry-University-Research Cooperation
}

\author{
ZHANG Linlin $^{1, a}$, ZHAO Haiming ${ }^{1,2, ~}{ }^{*}$, LIAO Xiaole ${ }^{1, b}$, Ji Yaqian ${ }^{1, c}$ \\ ${ }^{1}$ College of Mechanical and Electrical Engineering, Central South University, Changsha, 410083, \\ China \\ ${ }^{2}$ State Key Laboratory of High Performance Complex Manufacturing, Central South University, \\ Changsha, 410083, China \\ aemail: 984120969@qq.com, Corresponding author*email:

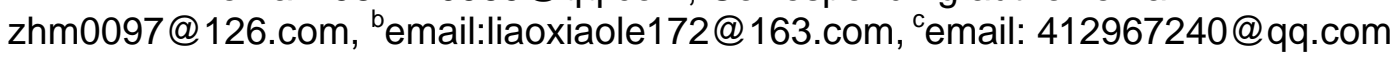

Keywords: Industry-university-research cooperation; Scientific and technological innovation service mode; Intermediary service institution

\begin{abstract}
The development mode of industry-university-research cooperation is the key strategy mind to become scientific and technological (sci-tech) power country. However, there is much resistance in the industry-university-research cooperation activities. Leading intermediary service institution to sci-tech innovation service mode constructed from the industry-university-research cooperation can accelerate the commercialization of research achievements and increase the scientific and technological level of industrial cluster. Then it can promote the development of regional economy. The main elements and characteristics of this sci-tech innovation service mode are analyzed from the beginning of activities to specific operation in the scientific innovation activities. Then it is considered to be successful by the example "High efficiency and energy saving vertical roller mill”.
\end{abstract}

\section{Introduction}

The industry-university-research cooperation is a positive cycle of scientific research, product, market and scientific research with the principle of pooling-of-interest, risk-sharing, complementary advantages and joint development [1]. Its technological innovative subjects are enterprises, university institutes and government. The three main subjects of industry-university-research cooperation have particular generalities as well as their own characteristics. It is the generalities that lead them to the same way while their own characteristics make them have significant dependence relationships. Resource-sharing, complementary advantages and persistence of industry-university-research cooperation guiding sci-tech innovation are objective requirements accord with whole development of modern society.

The study of industry-university-research cooperation in other country starts earlier than China. At present, they have more sci-tech industrial projects, wider coverage area and complete auxiliary facilities. They also have sound sci-tech innovation service institution, which can effectively organize each unit of industry-university-research cooperation. This may improve the working efficiency of projects and accelerate the process of sci-tech industrialization. The sci-tech innovation service institutions in many countries such as European Union tend to regional integrative development. Formerly, research resources in European Union are decentralized and information communication of research activities is inadequate, which caused much repeat of research work and the sci-tech resources unable to be used effectively. Hence, the European Union has set out a series of fruitful joint-action plan and a R\&D system to serve the sci-tech innovation and to expand the advantage of integral resources to other countries [2].

By contrast, the current situation of industry-university-research cooperation in China is not very good. For example, thousands of sci-tech achievements urgently needed by enterprises can't be met. While, mass achievements of universities and institutes can't be utilized [1]. The reason is that scientific innovation institutes based on industry-university-research cooperation didn't play the 
junction role. Thus, constructing the sci-tech innovation service mode based on industry-university-research cooperation and connecting the three main bodies of industry-university-research cooperation together are important to push the activities of industrial clusters.

\section{Main elements and features of sci-tech innovation service mode}

Sci-tech innovation service mode based on industry-university-research cooperation is a service system established center on industry-university-research cooperation. Enterprise, university and scientific research institute are deemed to the three main bodies of industry-university-research cooperation. Nevertheless, the three bodies can't ensure the successful conduct of industry-university-research cooperation projects individually which will be easily disinter-mediated. Besides the three main bodies, there is another bridge that sci-tech innovation service mode need, which is the intermediary service institute. Through catalyzing the develop of project of industry-university-research cooperation and solving problems concerning technical communication and market expanding, the industrialization of sci-tech achievements can be promoted. The four main elements each have its particular resource advantages:

(1) Enterprise resources: having the whole production equipment, specialized production technical personnel, specialized market-development talent, financial and material resources, information resources, management resources, controlled-market resources, internal environment resources, industry resources, external environment resources, but lack of some primary theory research, making the technology limited;

(2) University resources: having abundant primary research achievements, mass theory researcher, advanced experiment equipment, a unfailing supply of talent cultivation, but lack of experience and platform of sci-tech industrialization;

(3) Research institute resources: having frontier and specialized theory achievements, specialized technical personnel, but lack of transmit talent of technical achievement and market-need information;

(4) Sci-tech innovation service institute resources: complete information resource library, abundant industrialization experience, compound personnel team, but lack of sci-tech troubleshooter and matched production and experiment equipment.

\section{Cooperative relationships in sci-tech innovation service mode}

Based on the large core leading enterprises in the industry cluster, the innovative service mode has focused its service on small and medium enterprises [3]. The bridge involved in the cooperation is the sci-tech service institution whose intelligence and talent is introduced from colleges and universities and scientific research institutions. Intermediary service organization is the important component of national innovation system. Construction of the sci-tech service institution aims to integrate sci-tech system, advanced management committee and other resources to build a sci-tech innovative service window. The sci-tech innovative service window integrates drug pipeline, project consulting, intellectual property services, cultivation of new high-tech enterprises, incubation of sci-tech enterprises, technology transfer, achievement transformation and sci-tech financial service [4]. It can effectively help the enterprises to solve technological and informational problems as well as funds and talents in the innovation process. It therefore improves the innovation ability and competitiveness of the enterprises and perfects the innovation system, as well as promotes the upgrading of high-tech innovative industrial cluster.

Cooperative relationships between the subjects of sci-tech innovation service mode are shown as Fig1: 


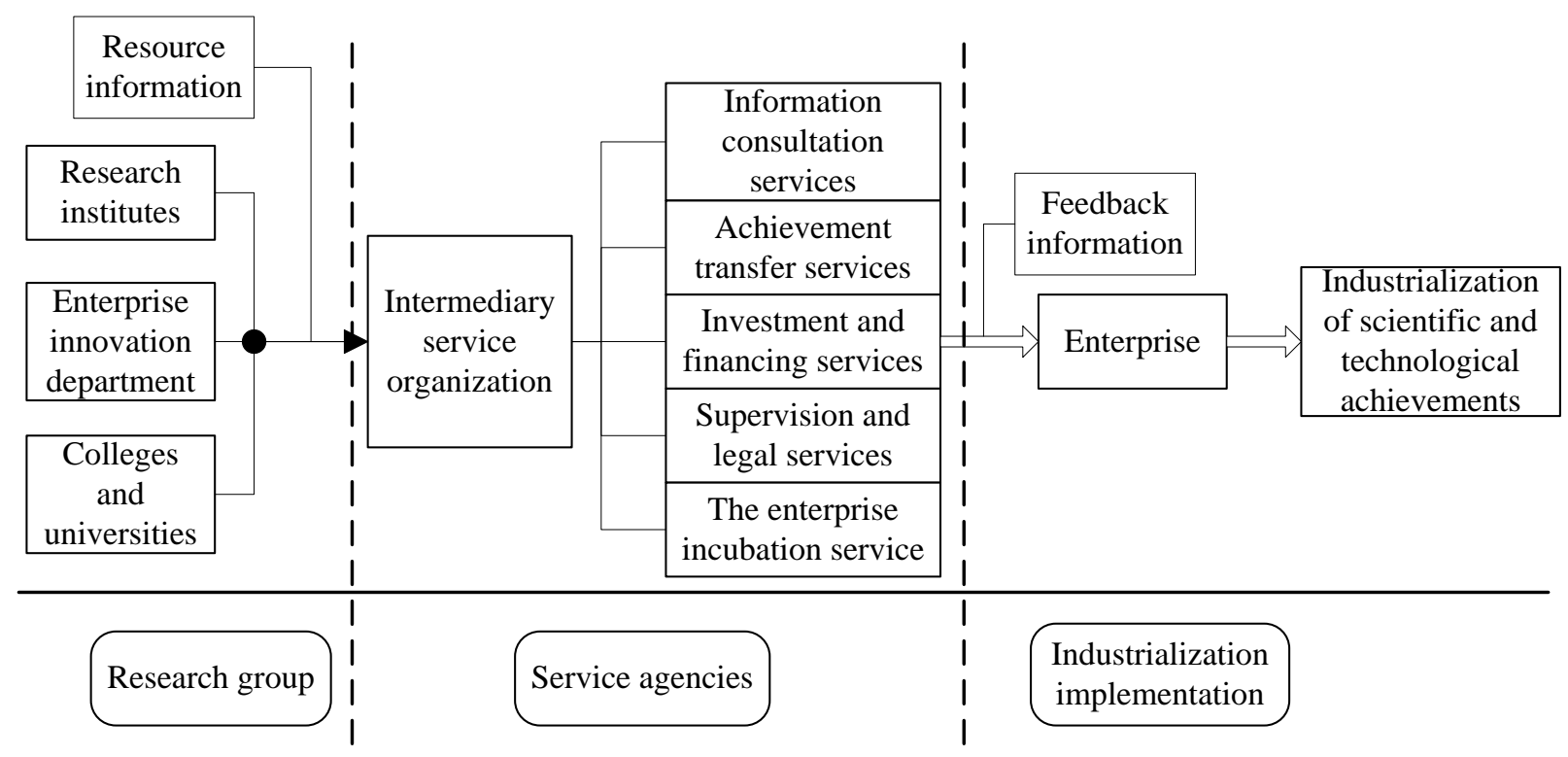

Fig1. Cooperation relationship among various units in the service mode

The sci-tech service institution functions as the bridge and link of the transmission and diffusion of technology and information between the supply and requisitioning parties to accelerate the transformation of sci-tech achievements. In the marketed economic system, on the basis of professional knowledge and specialized skills, the sci-tech service institution establishes close contact with all kinds of innovative subjects and factor market to provide supportive service for sci-tech activities. Hence it can effectively reduce the risk of innovation and accelerate the industrialization of sci-tech achievements [5].

\section{Launch and operation of sci-tech innovation service activities}

With strong centralized resources superiority, the industrial cluster has the resources to carry out sci-tech innovation activities. But it needs the organization's cooperation of the whole system to accomplish the integration and utilization of resources. The sci-tech service institution is an intermediary service institution based on the coordinated development of industrial cluster. It can effectively organize various units in the industrial clusters to promote the industrialization of sci-tech achievements. In the process of coordinated development in sci-tech innovation service, technical demands are firstly put forward by enterprises and then fed back to the relevant sci-tech service institution. Subsequently, the sci-tech service institution seeks the technique supplier with its comprehensive information base. In this process, colleges and universities, research institutes and relevant enterprises and institutions can make their resource superiority yield the best. The whole process is fast and efficient which can greatly save the time cost. The core contents serviced by the intermediary service institution are: integrating the various superior resources and completing cooperation requirements of relevant project with the principles of service agencies to promote, voluntary combination, contract connection, and jointly-constructed entity [6]. In the whole process, the sci-tech service institution has served as the middle bridge and promoted the launch and operation of sci-tech innovation service activities.

In the operation of sci-tech innovation service activities, the intermediary service institution mainly starts work from three parts: information collection, establishment of business partnership, and industrialization operation. The three parts are also the core service resources of the intermediary service institution.

\section{Information Collection.}

During and late of the project operation, there will be a large amount of information, then the ability to firstly grasp and reasonably deal with this information is an important criterion to measure whether the institution can make the project operate reasonably. Thus, it is indispensable in the agency. Information collection includes two parts: the original information and dynamic one. The 
original information, included in the organization of information resource, is a collection of the basic information of enterprise, research institutes, colleges and universities, and dynamic information is a collection of recent dynamic activities of various units. The first one is the standpoint of sci-tech innovation institutions, which belongs to the fixed resources of the organization. While the dynamic information is resource that meets the project needs of operation. Thus, it is constantly changing with the project progress.

1) In the early process: Firstly, we need to master the sponsor of the project--enterprise information, and its technical requirements, the first step in the whole project operation. Then, we use the original information repository to be screened for universities or research institutes that meet the requirements of the project to form a technical innovation team.

2) In the medium term: During the progress, the collection of the re-configuration of material resources, the training of workforce, the project progress, capital integration and other information is conducive to the parties to negotiate a plan and come up with a reasonable solution to make the project complete with high quality and efficiency.

3) In the post process: Mainly involving in a summary and processing of information needed to achieve industrialization of the product, the implementation of the project contract and the using information of the funds and resources.

Now, we have entered the information era, information collection must be together with the tools of information processing. Internet has connected the whole world. Innovative service organizations should establish specialized information network platform which can be used to collect and process the information and provide a series of unified collaborative R \& D internal standards and a net platform by which we can exchange ideas about research and development, and share knowledge. After that we can achieve seamless docking between the technical requirements of various units. A unified PDM architecture can support efficient and stable application of all R \& D personnel within the cluster [7].

\section{Establishment of partnership based on Herd Behavior.}

Lacking effective communication mechanism between the initiator and the technical provider of the project results in the establishment of partnerships hampered. In a regionalized business cluster, there are not only some relative concentration business units, but also a number of universities and research institutes. The common needs of technological innovation let them have the basic conditions for mutual cooperation.

Study on the herding behavior in entering creative industrial cluster of cluster partner [8] provides theoretical guidance for the establishment of the relationship between the commercial partners in the industrial clusters. In the industrial cluster, the performance of the cooperative partners is divided into three categories: joining the herd, rejecting to join the herd and having not joined the herd. The main factor that promotes the herding is incentive. Each individual in the cluster hope to join the group under certain incentive conditions. In the cluster, the units should take incentive measures to make the cluster partners overcome the negative emotions and make them be sensitive enough for market information. After that, they will join the herd.

Technological innovation service organization can provide the needed environment of industrialization process including the financial, market, legal and regulatory environment and the distribution of benefit environment to complete the project. Driven by this cooperative environment, business partnership based on herding behavior theory also will be naturally built. Under the condition of rational distribution of interests, these business partnerships are expected to continue for a long time, and will be long-term effective through establishing contracts and other forms of business cooperation [9].

\section{Industrialization Operation.}

Industrial operation of technology products is the ultimate goal of sci-tech innovation. For most small and medium enterprises, they can't complete the industrial operation of sci-tech products under the big market environment because of their own strength. The industrial operation is a complex commercial project, involving market development, financing, product promotion, patent application, sales, service and many other aspects. These are specialties of the technological 
innovation service agency, which have a professional team of industrial operation and be able to provide finance and business administration service and solve industrial operation problem. In the process of industrialization operation, science and technology service organization can help enterprises quickly realize the industrialization of sci-tech products, but also can drive the rapid development of other units (such as financial institutions, information consultancy, investment companies, etc.).

High efficiency and energy saving vertical roller mill has a number of patents. The original $\mathrm{R} \&$ $\mathrm{D}$ of this product is only a technologist in a small business. After many years of efforts, he made a prototype of the principle, and declared 5 invention patents. But there were still some key technical difficulties that can't be overcome. The efficiency and stability of the product can't meet the requirements. Subject to technical constraints, the product can't be perfect and pushed to the market for many years. Later he contacted the relevant experts of Central South University through Changsha Sea joint investment consulting Management Co., Ltd. They helped solve the technical problems of the product and improve the stability and the automation level of the product. He established Shaoshan Shao Yuan energy-saving heavy equipment Co., Ltd. through investment funds and improved the production conditions. The product has been successfully promoted to the market. Now the equipment has been successfully used in Xiangtan manganese mine, with the significant characteristics of high energy saving and efficiency. Powder fineness reached 300 meshes. Compared with the total power of ball mill motor and Raymond machine with the same capacity, it reduces energy consumption by 50\% 60\% and increases efficiency from 20\% to 30\%. It has a good market prospects.

Among the country, there are a lot of sci-tech services like this. They continue to provide fertile soil for the innovation and development of sci-tech enterprises, and help enterprises to improve technological innovation capability.

\section{Innovation of service mode in project engineering}

The concrete implementation of the project is different according to the work ability of enterprises. In order to improve the project implementation efficiency and make use of the research resources effectively, they launch innovation patterns of large enterprises' modular service as well as small and medium enterprises' one-stop service.

\section{Modular service of large enterprises.}

Large enterprise itself has relatively perfect facilities and abundant staffing. But due to the expansion of business or project involving a wide range, there are still quite a number of business problems unable to complete with high efficiency and good quality by itself. Modular service mode is raised for the problem of large enterprises in the process of business operation. The project is divided into several modules, and the enterprise and intermediary service agencies are responsible for different modules respectively. This modular mode can not only reduce project time, improve efficiency, but reasonably use mediation resources of the enterprise and the parties to promote balanced development among regions.

\section{One-stop service of small and medium-sized enterprises.}

Compared to large companies, small and medium-sized enterprises have small development scale, low allocation of resources and market share, lack of perfect service facilities. From the perspective of long-term development, to expand the business market is the only way to develop. Against the contradiction between the two, we propose a one-stop service mode for small and medium-sized businesses. One-stop service mode is divided into two ways that are both suitable for small and medium-sized enterprises: one is to all the work of a specific project and the other is to a certain type of business of all projects. In order to expand the scale, enterprises can increase the volume of business appropriately and give some of their businesses that out of their ability to the service institutions. And they themselves provide hardware facilities needed only. The cooperation mechanism can save a dedicated team for small and medium enterprises, and increase the volume for the business enterprise as well as open up the market for services. 


\section{Summary}

The sci-tech innovation service mode is based on industry-university-research. It introduces the intermediary service agency, which promotes market economy to accelerate development. In industrial cluster, this kind of mode can catalyze sci-tech innovation activities and promote the industrialization of sci-tech achievements. This paper studies the cooperation relationship among various units in this service mode and analyses the concrete operation of sci-tech innovation activities. Then it is demonstrated by the examples "High efficiency and energy saving vertical roller mill” that this kind of service mode is successful. At last, it puts forward different service patterns related to different groups, which can more quickly and effectively promote the development of science and technology. Science and technology service mode needs to make adjustments in accordance with the continuous changes in sci-tech development. After that, we can maximize the advantage of each resource and accelerate the industrialization of sci-tech achievements.

\section{Acknowledgements}

This work is supported by the national science and technology support plan industry cluster technology innovation service platform under the support of common key technology research and development 2012BAH11F01, China.

\section{References}

[1] LI Zhi-qiang, LI Lingji. A New Trend of the University-Industry-Science Partnership[J]. TSINGHUA JOURNAL OF EDUCATION, 2005,26(4):97-103.

[2] Dan Ying,Zhand Xinmin. Information Service Industrial Innovation of the European Union's S\&T Information Organizations [J]. CHINA INFORMATION REVIEW, 2006(3):32-35+55.

[3] Chen Shun. The Theoretical and Empirical Study of Innovation and Development of Private Enterprises Clusters-Taking Northeast China As An Example [D]. Northeast Normal University, 2006.

[4] Li Yifen,Shi Min, Huang Liping. Research on the construction of science and technology innovation service platform in high tech park [J]. COASTAL ENTERPRISES AND SCIENCE \& TECHNOLOGY, 2013,(2):14-16.

[5] Bridging Technology and Economy Development,Promoting Innovation Consensus and Practice[J]. Science and Technology Management Research, 2012(13):24-28.

[6] Liu Hailin. A Game Theory Analysis of Industry-University-Research Cooperation [D]. Wuhan University of Technology, 2006.

[7] Dou Runliang. The study of distributed PDM system based on WEB technology [D]. Tianjin University, 2003.

[8] LI Yu-hua, HU Yao-ying, TAN Jin-yan. Study on the herding behavior in entering creative industrial cluster of cluster partner [J]. Science-Technology and Management, 2012, 14(4):24-28.

[9] Shen Bi- yang, Chi Ren- yong. The enterprise's innovation network: new technology innovation research paradigm [J]. Science Research Management, 2005, 26(3):84-91. 